\title{
PEMILIHAN PERUSAHAAN JASA PENGIRIMAN BARANG TERBAIK MENGGUNAKAN METODE TOPSIS
}

\author{
Irianto \\ Sekolah Tinggi Manajemen Informatika Komputer Royal Kisaran, Asahan \\ Irianto2121212@gmail.com
}

\begin{abstract}
Abstrak - Peningkatan pengguna internet diseluruh Indonesia membuat makin meningkat pula pembelian barang secara online. Barang yang dibeli secara online sebagian besar menggunakan jasa pengiriman barang. Dengan banyaknya perusahaan yang menekuni jasa pengiriman barang, seperti JNE, TIKI, POS, DAN CARGO, membuat pengguna mendapatkan banyak alternatif untuk menggunakan jasa pengiriman barang. Banyak faktor yang mempengaruhi bagi pengguna online pada pemilihan jasa pengiriman barang, seperti lama pengiriman, harga yang ditawarkan, pelayanan yang diberikan, hingga reputasi perusahaan.
\end{abstract}

Kata kunci - SPK, Topsis, Jasa Pengiriman Barang

Abstract - Increasing internet users throughout Indonesia is also increasing the purchase of goods online. Goods purchased online mostly use goods delivery services. With many companies that pursue goods delivery services, such as JNE, TIKI, POS, AND CARGO, making users get many alternatives to use freight services. Many factors that affect online users on the selection of goods delivery services, such as the length of delivery, the price offered, the services provided, to the reputation of the company.

Keywords - SPK, Topsis, Delivery Service

\section{PENDAHULUAN}

Perusahaan menjadi salah satu bidang atau sector penghasilan yang cukup banyak di Indonesia, salah satu jenis perusahaan yang cukup dikenal adalah perusahaan jasa yang bisa sangat mudah dijumpai. Dalam era globalisasi dan teknologi dewasa ini, perusahaan jasa pengiriman barang sangat dibutuhkan keberadaannya hampir disetiap aspek kehidupan manusia. Khususnya dibidang jual beli yang menjadi kebutuhan bagi para produsen untuk memenuhi permintaan konsumen yang selalu menggunakan jasa pengiriman barang baik melalui transportasi darat, laut dan udara, banyak terdapat di beberapa daerah di Indonesia dengan keberadaan jasa pengiriman barang yang sangat diminati oleh masyarakat diantaranya ada jasa pengiriman barang seperti "JNE, TIKI, POS, DAN CARGO”.

Menurut Abdul Kadir Muhammad Perusahaan adalah tempat terjadinya kegiatan produksi dan berkumpulnya semua faktor produksi. Dalam UU No 3 Tahun 1982 tentang wajib Daftar Perusahaan Pasal 1 huruf $b$, dirumuskan bahwa perusahaan adalah 
setiap bentuk usaha yang menjalankan setiap jenis usaha yang tetap dan terus menerus dan yang didirikan, bekerja serta berdudukan dalam wilayah Negara Republik Indonesi untuk tujuan memperoleh keuntungan dan laba. Menurut salah satu pakar bernama Adrian Payne Jasa ialah aktivitas ekonomi yang mempunyai nilai atau manfaat intangible yang berkaitan dengannya, melibatkan interaksi dengan konsumen atau dengan barang milik tapi tidak menghasilkan transfer kepunyaan atau kepemilikan.

Secara umum jasa adalah pemberian suatu tindakan atau kinerja yang kasap mata dari satu pihak ke pihak lainnya. Secara bersamaan jasa dikonsumsi pada kedua pihak lainnya dimana interaksi pemberi jasa dan yang menerima jasa mempengaruhi hasil jasa tersebut. Adapun kegiatan yang di identifikasikan yang sifatnya abstrak atau tak terlihat yang direncanakan untuk memenuhi kepuasan pihak tertentu. Secara umum Jasa pengiriman adalah segala upaya yang diselenggarakan atau dilaksanakan secara sendiri atau secara bersama - sama dalam suatu organisasi untuk memberikan pelayanan secara efektif dan efisien. Di Indonesia jasa pengiriman barang/jasa ekspedisi sangatlah penting karena luas daerah indonesia dan terdiri dari banyak pulau. Maka jasa ekspedisi/pengiriman barang sangat mendukung efektif dan efisien waktu.

Oleh karena itu dibuatlah salah satu jalan yang paling efektif untuk memperoleh hasil yang maksimal adalah menggunakan teknologi internet. Saat ini di internet digunakan dalam berbagai bidang kehidupan seperti bisnis, pendidikan, perbankan, dan lain sebagainya. Pemilihan jasa pengiriman barang sangatlah penting dan harus sesuai dengan kriteria dan kategori jasa pengiriman yang di inginkan, untuk itu masyarakat dituntut agar lebih bijak dalam memilih jasa pengiriman agar terhindar dari penipuan sejumlah jasa pengiriman yang tidak resmi. Terkadang proses pengiriman barang tidak sesuai dengan prosedur waktu yang telah ditentukan, dan bahkan ada juga jasa pengiriman barang yang tidak bisa langsung sampai ke lokasi penerima namun harus mengambil ke kantor cabang jasa pengiriman setempat.

\section{A. Rumusan Masalah}

Berdasarkan latar belakang masalah di atas, maka rumusan masalah dalam penelitian ini adalah sebagai berikut :

a. Bagaimana memilih Perusahaan Jasa Pengiriman Barang Terbaik untuk memenuhi kebutuhan masyarakat dalam hal pengiriman barang?

b. Bagaimana menerapkan Pemilihan Perusahaan Jasa Pengiriman Barang Terbaik dengan menggunakan metode topsis?

\section{B. Sistem Pendukung Keputusan (Decision Support} System)

Decision Support System didefinisikan sebagai sistem computer yang mampu memberikan kemampuan baik kemampuan pemecahan masalah maupun kemampuan pengkomunikasian untuk masalah semi terstruktur. Secara khusus, DSS didefinisikan sebagai sebuah sistem yang mendukung kerja seorang manager maupun sekelompok manager dalam memecahkan masalah semi terstruktur dengan cara memberikan informasi ataupun usulan menuju pada keputusan tertentu.

DSS ini bisa berbentuk sistem manual maupun sistem terkomputerisasi. Namun dalam buku ini ditekankan pada sistem penunjang keputusan yang pelaksanaannya berbasis pada komputer. Dari definisi diatas bisa disimpulkan bahwa tujuan DSS dalam proses pengambilan keputusan adalah:

a. Membantu menjawab masalah semi-terstruktur

b. Membantu manajer dalam mengambil keputusan, bukan menggantikannya 
c. Meningkatkan efektifitas pengambilan keputusan seorang manajer dari pada efisiensinya.

\section{Karakterisitik Sistem Pendukung Keputusan}

Karakteristik dari sistem pendukung keputusan

(DecisionSupport System) adalah sebagai berikut :

a. Tujuan utama dari Sistem Pendukung Keputusan adalah untuk memperbaiki mutu keputusan serta performance. Sistem Pendukung Keputusan tidak hanya sekedar menyajikan informasi yang lebih banyak, lebih baik dan lebih akurat pada waktu yang tepat saja.

b. Sistem Pendukung Keputusan ditujukan untuk environment yang komplek, kurang terstruktur dan bahkan politis sifatnya.

c. Sistem Pendukung Keputusan bertumpu pada laporan perkecualian dan macamnya untuk menunjang proses identifikasi masalah.

d. Sistem Pendukung Keputusan berkombinasi "modelling" dan teknik-teknik analisa yang lain dengan fungsi penyajian kembali data.

e. Sistem Pendukung Keputusan berfokus pada prinsip "mudah dipakai" dan "fleksibel” dalam berhadapan dengan pemakai tertentu atau sekelompok pemakai.

f. Proses Pengambilan Keputusan.

\section{Konfigurasi Sistem Pendukung Keputusan (Decision Support System)}

Terdapat 3 komponen utama, yaitu data management, model management, dan user interface. Aliran kerja dari DSS ini adalah sebagai berikut:

a. Data management melakukan pengambilan data yang diperlukan baik dari database yang berisi data internal maupun database yang berisi data eksternal. Jadi, fungsi komponen data disini jelas sebagai penyedia data yang diperlukan oleh sistem DSS b. Model management melalui model base management melakukan interaksi baik dengan user interface untuk mendapatkan perintah maupun data management untuk mendapatkan data yang akan diolah. Model base management akan menggunakan model base yang berisi model-model yang digunakan dalam DSS yang dengan bantuan perangkat lunak atau engine yang ada di dalam modeling tools melakukan pengolahan data yang kemudian hasilnya dikembalikan lewat model base management untuk dikirim ke user interface.

c. User interface digunakan untuk berinteraksi antara user dengan DSS, baik untuk memasukkan informasi ke sistem maupun menampilkan informasi ke user. Karena begitu pentingnya komponen user interface bagi suatu sistem DSS, maka kita harus bisa merancang suatu user interface yang bisa mudah dipelajari dan digunakan user dan laporan yang bisa secara mudah dimengerti oleh pengguna

Pada pengertian diatas dapat dijelaskan bahwa sistem pendukung keputusan bukan merupakan alat pengambilan keputusan, melainkan merupakan sistem yang membantu pengambil keputusan dengan melengkapi mereka dengan informasi dari data yang telah diolah dengan relevan dan diperlukan untuk membuat keputusan tentang suatu masalah dengan lebih cepat dan akurat. Sehingga sistem ini tidak dimaksudkan untuk menggantikan pengambilan keputusan dalam proses pembuatan keputusan.

a. Tahapan SPK :

1. Definisi masalah

2. Pengumpulan data atau elemen informasi yang relevan 
3. Pengolahan data menjadi informasi baik dalam bentuk laporan grafik maupun tulisan

4. Menentukan alternatif-alternatif solusi (bisa dalam persentase).

b. Tujuan dari SPK :

1) Membantu menyelesaikan masalah semiterstruktur.

2) Mendukung manajer dalam mengambil keputusan.

3) Meningkatkan efektifitas bukan efisiensi pengambilan keputusan.

Dalam pemrosesannya, SPK dapat menggunakan bantuan dari sistem lain seperti Artificial Intelligence, Expert Systems, Fuzzy Logic, dll.

\section{E. Technique for Order Preference by Similarity to} Ideal Solution (Topsis)

Topsis diperkenalkan pertama kali oleh Yoon dan Hwang pada tahun 1981 untuk digunakan salah satu metode dalam memecahkan masalah multikriteria (Sachdeva, 2009). Topsis adalah salah satu metode pengambilan keputusan multikriteria atau alternatif pilihan yang merupakan alternatif yang mempunyai jarak terkecil dari solusi ideal positif dan jarak terbesar dari solusi ideal negatif dari sudut pandang geometris dengan menggunakan jarak Euclidean. Namun, alternatif yang mempunuyai jarak terkecil dari solusi ideal positif, tidak harus memberikan jarak terbesar dari solusi ideal negatif.

Langkah-Langkah Metode Topsis

1. Pada langkah ini, proses dilakukan dimulai dengan menghitung bobot setiap kriteria.

Tabel 1 Keterangan Nilai Bobot

\begin{tabular}{|l|l|}
\hline 1 & Sangat Rendah \\
\hline 2 & Rendah \\
\hline
\end{tabular}

\begin{tabular}{|l|l|}
\hline 3 & Cukup \\
\hline 4 & Tinggi \\
\hline 5 & Sangat Tinggi \\
\hline
\end{tabular}

2. Buat sebuah matriks xij yang terdiri dari $\mathrm{m}$ alternatif dan $\mathrm{n}$ kriteria.

Tabel 2 Perbandingan alternative dan kriteria

\begin{tabular}{|l|l|l|l|l|l|}
\hline $\begin{array}{c}\text { Alternative/ } \\
\text { kriteria }\end{array}$ & K1 & K2 & K2 & K3 & K4 \\
\hline A1 & & & & & \\
\hline A2 & & & & & \\
\hline A3 & & & & & \\
\hline A4 & & & & & \\
\hline
\end{tabular}

3. Hitung Matriks Keputusan ternormalisasi

$$
r_{i j}=\frac{x_{i j}}{\sqrt{\sum_{i=1}^{m} x_{i j}^{2}}}
$$

Gambar 1 Rumus Menghitung Matriks Ternormalisasi

4. Hitung Matriks Keputusan ternormalisasi dan terbobot.

$$
v_{i j}=r_{i j} \times w_{j}
$$

Gambar 2 Rumus Menghitung Matriks

Ternormalisasi Terbobot

5. Mencari nilai maksimal dan minimal dari normalisasi terbobot.

6. Mencari D+ dan D- untuk setiap alternatif. 
$D x+=\sqrt{(A x C 1-Y 1+)^{2}+\left(A x C 1-Y_{2}+\right)^{2}+\cdots+\left(A x C n-Y_{n}+\right)^{2}}$

Gambar 3 Rumus Menghitung Solusi Ideal Positif

$D x+=\sqrt{(A x C 1-Y 1-)^{2}+\left(A x C 1-Y 2^{-}\right)^{2}+\cdots+\left(A x C n-Y_{n-}\right)^{2}}$

Gambar 4 Rumus Menghitung Solusi Ideal Negatif

7. Mencari Hasil ( merangking alternative)

$$
\mathrm{V} x=\frac{D x-}{(D x-)+(D x+)}
$$

Gambar 5 Rumus Menghitung Preferensi

\section{HASIL DAN PEMBAHASAN}

Sistem Pendukung Keputusan Pemilihan Peusahaan Jasa Pengiriman Barang Terbaik merupakan suatu sistem yang akan menentukan hasil perhitungan melalui metode topsis. Adapun proses pemilihan tersebut mempertimbangkan beberapa kriteria diantaranya biaya, layanan, jarak tempuh dan akses. Ada juga beberapa alternatif yang digunakan yaitu cargo, Pos, JNE dan TIKI.

Tabel 3 Bobot Kriteria

\begin{tabular}{||c|c|c|c|c||}
\hline Kriteria & Biaya & Layanan & Jarak Tempuh & Akses \\
\hline Bobot & 5 & 4 & 3 & 2 \\
\hline
\end{tabular}

Tabel 4 Bobot Alternative

\begin{tabular}{|c|c|c|c|c|}
\hline A/K & Biaya & Layanan & Jarak Tempuh & Akses \\
\hline Cargo & 5 & 4 & 3 & 2 \\
\hline Pos & 4 & 3 & 5 & 1 \\
\hline JNE & 4 & 4 & 3 & 2 \\
\hline TIKI & 3 & 3 & 3 & 2 \\
\hline
\end{tabular}

Langkah Selanjutnya yaitu menentukan matriks ternormalisasi sebagai berikut :

Tabel 5 Matrik Ternormalisasi

\begin{tabular}{|c|c|c|c|c|}
\hline A/K & Blaya & Layanan & Jarak Tempuh & Akses \\
\hline Cargo & 0,615457455 & 0,565685425 & 0,41602515 & 0,554700196 \\
\hline Pos & 0,492365964 & 0,424264069 & 0,69337525 & 0,277350098 \\
\hline NE & 0,492365964 & 0,565685425 & 0,41602515 & 0,554700196 \\
\hline TIKI & 0,369274473 & 0,424264069 & 0,41602515 & 0,554700196 \\
\hline
\end{tabular}

Langkah Selanjutnya yaitu menentukan matriks ternormalisasi terbobot sebagai berikut :

Tabel 6 Matriks Ternormalisasi Terbobot

\begin{tabular}{|c|c|c|c|c|}
\hline A/K & Blaya & Layanan & Jarak Tempuh & Akses \\
\hline Cargo & 3,077287274 & 2,2627417 & 1,24807544 & 1,109400392 \\
\hline Pos & 2,46182982 & 1,697056275 & 2,08012574 & 0,554700196 \\
\hline JNE & 2,46182982 & 2,2627417 & 1,24807544 & 1,109400392 \\
\hline TIKI & 1,846372365 & 1,697056275 & 1,24807544 & 1,109400392 \\
\hline
\end{tabular}

Langkah Selanjutnya yaitu menentukan nilai mak dan min berdasarkan tabel 6

Tabel 7 Nilai Max dan Min

\begin{tabular}{||c|c|c|c|c||}
\hline \hline ket & Biaya & Layanan & Jarak Tempuh & Akses \\
\hline MAX & 3,077287274 & 2,2627417 & 2,08012574 & 1,109400392 \\
\hline \multicolumn{5}{|l|}{} \\
\hline MIN & 1,846372365 & 1,697056275 & 1,24807544 & 0,554700196 \\
\hline \hline
\end{tabular}

Langkah selanjutnya adalah mencari nilai jarak ideal positif dan jarak ideal negatif sebagai berikut :

Tabel 8 Ideal Positif dan Negatif

\begin{tabular}{|c|c|c|c|c|c|}
\hline \multirow{4}{*}{$\mathrm{D}+$} & Cargo & 0,832050294 & \multirow{4}{*}{ D. } & Cargo & 1,4638456 \\
\hline & POS & 1,003234861 & & POS & 1,0349375 \\
\hline & $\mathrm{NE}$ & 1,034937472 & & $\mathrm{NE}$ & 1,0032349 \\
\hline & TIKI & 1,00154941 & & TIKI & 0,5547002 \\
\hline
\end{tabular}


Berdasarkan tabel 8 di atas, kemudian mencari nilai prevrensi sebagai berikut :

Tabel 9 Hasil Akhir

\begin{tabular}{|l|c|}
\hline \multicolumn{1}{|c|}{ Alt } & $\mathrm{V}$ \\
\hline Cargo & 0,637592318 \\
\hline POS & 0,507777216 \\
\hline JNE & 0,492222784 \\
\hline TIKI & 0,356433951 \\
\hline
\end{tabular}

Pada Tabel 9 tersebut dapat dilihat bahwa alternative untuk menentukan Pemilihan Perusahaan Jasa] Pengiriman Barang Terbaik adalah Cargo menempati urutan pertama dengan nilai 0.637592318, urutan kedua yaitu mobil Hyundai grand avega dengan nilai 0.507777216,urutan ketiga mobil avanza dengan nila1 0.492222784 urutan keempat mobil xenia dengan nilai 0.35643395. Berdasarkan hasil penelitian yang] dilakukan menggunakan Metode Topsis, maka keputusan yang diambil untuk menentukan Pemilihan Perusahaan Jasa Pengiriman Barang Terbaik ialah Cargo.

\section{KESIMPULAN}

Berdasarkan hasil penelitian yang telah saya lakukan dapat disimpulkan sebagai berikut :

1. Beberpa kriteria yang telah dibentuk kemudian dijadikan sebagai standar Pemilihan Perusahaan Jasa Pengiriman Barang Terbaik diantaranya : biaya, layanan, jarak tempuh dan akses.

2. Hasil model perhitungan tersebut menggunakan Metode Topsis, dapat dikatakan bahwa Pemilihan Perusahaan Jasa Pengiriman Barang Terbaik adalah Cargo dengan menempati urutan pertama dengan nilai 0,63 , kemudian disusul oleh Pos yang menempati urutan kedua dengan nilai 0,50 .
Selanjutnya JNE menempati urutan ketiga yang nilainya 0,49 , dan TIKI menempati urutan keempat dengan nilai 0,35. Telah dipastikan bahwa berdasarkan penelitian yang saya lakukan menggunakan Metode Topsis, oleh karena itu secara otomatis untuk menentukan Pemilihan Perusahaan Jasa Pengiriman Barang Terbaik adalah Cargo.

\section{DAFTAR PUSTAKA}

Aulia, R., 2013, Sistem Pendukung Keputusan Seleksi Penerimaan Beasiswa Di STTH Medan, Seminar Nasional Teknologi Informasi dan Komunikasi (SNASTIKOM 2013), Medan, 13-14 Maret 2013.

Arus Akbar Silondae, Wirawan B.Ilyas. 2011. PokokPokok Hukum Bisnis. Jakarta: Penerbit Salemba Empat Kusrini, (2009)" Konsep dan Aplikasi Sistem Pendukung Keputusan” Andi Offset: Yogyakarta

Wei, J.. TOPSIS Method for Multiple Attribute Decision Making with Incomplete Weight Information in Linguistic Setting. Journal of Convergence Information Technology , V, 181186,2010 